\title{
A Review of Traditional Vaccine-Preventable Diseases and the Potential Impact on the Otolaryngologist
}

\author{
Christopher J. Greenlee ${ }^{1,2}$ Stephen S. Newton ${ }^{1,2}$ \\ ${ }^{1}$ Department of Otolaryngology, University of Colorado School of \\ Medicine, Aurora, Colorado, United States \\ 2 Department of Otolaryngology, Children's Hospital Colorado, \\ Aurora, Colorado, United States \\ Int Arch Otorhinolaryngol 2018;22:317-329. \\ Address for correspondence Stephen Newton, MD, Department of \\ Pediatric Otolaryngology, Children's Colorado Outpatient Specialty \\ Care at Briargate, 4125 Briargate Parkway, Colorado Springs, \\ CO 80920, United States \\ (e-mail: Stephen.Newton@childrenscolorado.org).
}

\begin{abstract}
Keywords

- vaccine

- otolaryngology

- public health

- disease outbreaks

- disease eradication

- vaccination

Introduction A majority of otolaryngologists have not had direct experience with many vaccine-preventable diseases since the creation of national vaccination programs. Despite the elimination of endemic transmission of some of these diseases in the United States, outbreaks can occur anywhere and still pose a threat to public health around the world. Recent outbreaks and changing trends in exemption rates indicate that it is important for physicians to maintain a working knowledge of how these diseases present and of the recommended treatment guidelines.

Objectives This review will evaluate the current state of vaccination rates, vaccine exemption rates and disease incidence in the United States and in the world. It will also examine the clinical presentation and treatment recommendations of these diseases. Data Synthesis United States estimated vaccination rates, vaccine exemption rates and vaccine-preventable disease incidences were obtained from data compiled by the Centers for Disease Control and Prevention. World vaccination rates and disease incidences were obtained from the World Health Organization databases, which compile official figures reported by member states. A PubMed literature review provided information on the current state of vaccination exemptions and outbreaks in the United States.

Conclusion Vaccination and vaccine exemption rates continue to put the United States and many areas of the world at risk for outbreaks of vaccine-preventable diseases. Clinical guidelines should be reviewed in the event of a local outbreak.
\end{abstract}

\section{Introduction}

Vaccines are often considered one of the greatest achievements in medicine and public health, and have helped to greatly reduce the incidence of several historically common infectious diseases. The inclusion of vaccinations in the standard of care guidelines has resulted in record low levels of vaccine-preventable disease (VPD) occurrences in the U.S. ${ }^{1}$ The use of vaccines can greatly reduce the risk of contracting

received

September 12, 2016

accepted

May 7, 2017

published online

July 25, 2017 one of these diseases at an individual level and when vaccination coverage is high enough, ${ }^{2,3}$ it can also confer herd immunity at a community and population level. For most diseases in which vaccinations are regularly used, cases of VPDs in the U.S. have been reduced by $90-100 \%$, with a similar reduction in deaths associated with these diseases. ${ }^{1}$ Similar reductions are seen around the world in countries that have developed robust vaccination programs.

Copyright $\odot 2018$ by Thieme Revinter Publicações Ltda, Rio de Janeiro, Brazil 
Worldwide progress is evident in the eradication of endemic poliomyelitis in all but three countries and the elimination of both measles and rubella from the World Health Organization (WHO) Region of the Americas in 2002. ${ }^{4,5}$ While these are significant advances in public health, most of these diseases are far from complete elimination and still pose a significant threat to all areas of the globe.

Individuals and physicians living in the U.S. and other countries with strong immunization programs are likely to lack any firsthand experience with many VPDs as it has been decades since diseases such as measles, mumps, rubella and diphtheria were commonplace. In the decade preceding the implementation of the national measles vaccine program, in 1963, it was estimated that there were 3 to 4 million cases of measles every year in the U.S., with an average of 500 deaths. ${ }^{6}$ Rubella was even more prevalent, with at least 12.5 million cases occurring in the mid-1960s and an estimated 20,000 children born with congenital birth defects as a result. ${ }^{7}$ To put this into perspective, the CDC data indicate that the highest reported yearly total of measles cases since the year 2000 is 667, which occurred in $2014 .^{8}$ The CDC also reports that there have been less than 100 reported cases of rubella in the U.S. in the past 10 years. This reduction in incidence leads to a decreased perception of the severity and individual susceptibility to these diseases. ${ }^{9}$ This distancing from the effects of these diseases may be one of the reasons that nonmedical exemptions (NMEs) are not only increasing, but increasing at a greater rate when compared with data going as far back as $1991 .{ }^{10}$ As more individuals choose the route of NMEs, there may be an increased likelihood of outbreaks.

A whole generation of physicians has trained after the time of near-universal vaccinations. Many otolaryngologists, like other physicians, are unlikely to have experience in diagnosing and treating patients with VPDs. As these patients often present with symptoms in the head and neck, it is important that otolaryngologists be reminded of these diseases. This lack of familiarity with these infections and their variable presentations can result in these patients being seen by an otolaryngologist without prior diagnosis. Because these VPDs can occur in both unvaccinated children and adults, patients may present at any age. Therefore, it is important that regardless of the patient population the otolaryngologist serves, familiarity with these diseases is accomplished.

This article will review the current state of vaccination rates and VPD rates in both the U.S. and the world. Additionally, this review will examine how these diseases might present and remind physicians of the current treatment guidelines.

\section{Review of Vaccination Rates and Disease Incidence}

The United States childhood vaccination rate estimates for the 19-35 months age group were obtained from data collected by the Centers for Disease Control's (CDC) National Immunization Survey (NIS). National kindergarten vaccina- tion rate data were obtained from publications within the CDC's Morbidity and Mortality Weekly Report (MMWR). World vaccination rates were obtained via annual reports from the World Health Organization (WHO) and the United Nations Children's Fund (UNICEF) joint reporting process. The WHO/UNICEF vaccination rate data represent official reports from the $194 \mathrm{WHO}$ member states that participate in the reporting process.

The vaccine preventable diseases incidence data for the U.S. were obtained through the annual Summary of Notifiable Diseases reports from the CDC's National Notifiable Diseases Surveillance System (NNDSS). The international VPDs incidence data were obtained from the WHO/UNICEF database of disease incidence, which collects reported cases from 194 participating WHO member states.

The national and state level vaccine exemption data for kindergarteners were obtained from the CDC's MMWR reports. A literature review of the current state of vaccination exemptions and the reasons parents choose to exempt children in the U.S. was conducted through a PubMed search using the key words "vaccine exemption," "medical exemption" and "nonmedical exemption."

Clinical information regarding the presentation of these diseases and the current treatment guidelines was obtained from the Red Book: Report of the Committee on Infectious Diseases and from the Manual for the Surveillance of Vaccine-Preventable Diseases published by the CDC.

\section{United States Vaccination Rates}

The most recent data from the CDC regarding U.S. vaccination rates for children (19-35 months) for the period of JanuaryDecember of 2014 contains vaccination rate estimations using NIS results. National and statewide vaccination levels are reported and can be found in - Table 1 .

Additional vaccination rate data provided by the CDC's MMWR reports were collected for children enrolled in kindergarten. Both national and statewide vaccination levels were reported and can also be found in - Table 1. Diphtheria, tetanus and pertussis (DTaP) vaccination rates were determined according to individual state regulations of either four or five required doses for enrollment in kindergarten. Data from Pennsylvania was not included as pertussis is not required for kindergarten.

\section{WHO/UNICEF Regional Vaccination Rates}

WHO/UNICEF vaccination rate data represent official national reports via the standardized Joint Reporting Form and draws from the most recently updated report released in July of 2015. The data are representative of all age groups. WHO/UNICEF regional vaccination rate estimates are summarized in - Table 2. Countries in the Americas region (North and South America) that had a notably low three dose DTaP vaccination rate were: Ecuador (83\%), Venezuela (78\%), Guatemala (73\%) and Haiti (48\%). Two dose measles-containing vaccine (MCV) rates were considerably lower, as over one third of the countries in the region reported a vaccination rate of less than $85 \%$. Haemophilus influenzae type b (Hib) (three doses) vaccination rates were similar to those seen 
Table 1 Estimated US vaccination rates for children aged 19-35 months in 2014 and children enrolled in kindergarten for the 2014-2015 school year.

\begin{tabular}{|c|c|c|c|c|}
\hline \multirow[b]{2}{*}{ State } & \multirow[b]{2}{*}{ DTaP 3rd dose (\%) } & \multicolumn{3}{|l|}{$19-35$ months $^{50}$} \\
\hline & & DTaP 4th dose (\%) & MMR 1st dose (\%) & Hib full series (\%) \\
\hline US National & $94.7 \pm 0.7$ & $84.2 \pm 1.2$ & $91.5 \pm 0.9$ & $82.0 \pm 1.3$ \\
\hline Alabama & $92.6 \pm 5.7$ & $84.1 \pm 7.4$ & $92.0 \pm 5.6$ & $85.3 \pm 7.0$ \\
\hline Alaska & $92.5 \pm 3.9$ & $78.7 \pm 6.3$ & $90.2 \pm 4.3$ & $80.8 \pm 6.2$ \\
\hline Arizona & $90.6 \pm 5.1$ & $81.4 \pm 6.4$ & $84.1 \pm 6.3$ & $77.0 \pm 7.1$ \\
\hline Arkansas & $93.8 \pm 3.3$ & $80.0 \pm 6.8$ & $89.1 \pm 5.4$ & $78.3 \pm 7.5$ \\
\hline California & $94.9 \pm 3.5$ & $87.3 \pm 5.3$ & $90.5 \pm 4.7$ & $84.7 \pm 6.0$ \\
\hline Colorado & $94.2 \pm 3.8$ & $85.4 \pm 4.9$ & $87.4 \pm 5.4$ & $85.3 \pm 5.3$ \\
\hline Connecticut & $94.8 \pm 4.3$ & $86.0 \pm 6.0$ & $93.2 \pm 4.6$ & $84.4 \pm 6.5$ \\
\hline Delaware & $95.0 \pm 4.0$ & $85.4 \pm 6.0$ & $90.8 \pm 4.8$ & $84.5 \pm 6.1$ \\
\hline Dist. of Columbia & $92.6 \pm 4.3$ & $80.6 \pm 6.6$ & $90.9 \pm 4.8$ & $80.9 \pm 6.9$ \\
\hline Florida & $98.3 \pm 1.5$ & $86.2 \pm 6.1$ & $91.2 \pm 4.8$ & $84.9 \pm 6.3$ \\
\hline Georgia & $94.9 \pm 3.9$ & $85.7 \pm 6.2$ & $94.2 \pm 3.9$ & $81.1 \pm 7.1$ \\
\hline Hawaii & $94.5 \pm 3.3$ & $82.4 \pm 5.9$ & $92.5 \pm 3.7$ & $84.5 \pm 5.1$ \\
\hline Idaho & $92.2 \pm 5.2$ & $77.7 \pm 7.2$ & $89.7 \pm 5.1$ & $80.4 \pm 6.5$ \\
\hline Illinois & $93.6 \pm 3.1$ & $87.8 \pm 3.9$ & $93.2 \pm 2.8$ & $82.8 \pm 4.6$ \\
\hline Indiana & $94.8 \pm 3.7$ & $82.8 \pm 5.7$ & $91.5 \pm 4.5$ & $82.0 \pm 5.7$ \\
\hline lowa & $93.4 \pm 4.8$ & $87.4 \pm 5.7$ & $91.1 \pm 5.2$ & $79.8 \pm 7.6$ \\
\hline Kansas & $92.1 \pm 5.0$ & $85.3 \pm 6.2$ & $93.4 \pm 4.0$ & $82.7 \pm 6.7$ \\
\hline Kentucky & $94.6 \pm 4.0$ & $83.2 \pm 6.5$ & $88.6 \pm 5.5$ & $79.7 \pm 7.2$ \\
\hline Louisiana & $95.4 \pm 3.5$ & $83.3 \pm 5.6$ & $91.8 \pm 4.1$ & $81.9 \pm 6.4$ \\
\hline Maine & $97.5 \pm 2.0$ & $93.1 \pm 3.5$ & $97.2 \pm 2.0$ & $90.5 \pm 4.1$ \\
\hline Maryland & $97.0 \pm 2.8$ & $85.4 \pm 6.4$ & $94.9 \pm 3.3$ & $86.2 \pm 6.1$ \\
\hline Massachusetts & $98.2 \pm 1.7$ & $89.8 \pm 5.0$ & $94.7 \pm 3.2$ & $86.8 \pm 6.0$ \\
\hline Michigan & $89.4 \pm 6.1$ & $77.7 \pm 8.1$ & $87.4 \pm 6.5$ & $77.4 \pm 7.7$ \\
\hline Minnesota & $95.3 \pm 3.9$ & $87.1 \pm 6.2$ & $94.3 \pm 4.2$ & $79.9 \pm 7.6$ \\
\hline Mississippi & $96.2 \pm 4.0$ & $83.3 \pm 7.6$ & $95.0 \pm 4.3$ & $80.3 \pm 7.9$ \\
\hline Missouri & $96.8 \pm 3.1$ & $79.2 \pm 7.3$ & $90.3 \pm 4.7$ & $77.6 \pm 7.5$ \\
\hline Montana & $95.9 \pm 3.5$ & $83.1 \pm 7.0$ & $93.4 \pm 4.4$ & $86.4 \pm 5.7$ \\
\hline Nebraska & $97.2 \pm 2.6$ & $87.3 \pm 5.4$ & $96.0 \pm 2.9$ & $87.7 \pm 5.0$ \\
\hline Nevada & $91.4 \pm 4.0$ & $81.0 \pm 5.8$ & $90.4 \pm 4.2$ & $78.8 \pm 5.9$ \\
\hline New Hampshire & $97.8 \pm 1.8$ & $91.3 \pm 4.2$ & $93.1 \pm 3.8$ & $91.9 \pm 4.1$ \\
\hline New Jersey & $97.5 \pm 2.1$ & $85.4 \pm 5.4$ & $93.3 \pm 3.8$ & $80.2 \pm 6.1$ \\
\hline New Mexico & $95.8 \pm 2.7$ & $87.5 \pm 5.1$ & $94.6 \pm 3.0$ & $87.2 \pm 5.4$ \\
\hline New York & $97.6 \pm 1.6$ & $85.4 \pm 4.0$ & $93.1 \pm 2.9$ & $80.5 \pm 4.5$ \\
\hline North Carolina & $96.5 \pm 3.5$ & $86.9 \pm 5.9$ & $94.3 \pm 4.1$ & $89.3 \pm 5.4$ \\
\hline North Dakota & $96.2 \pm 3.1$ & $81.8 \pm 6.2$ & $94.9 \pm 3.3$ & $80.8 \pm 6.3$ \\
\hline Ohio & $95.3 \pm 3.1$ & $85.1 \pm 6.0$ & $95.6 \pm 2.9$ & $81.4 \pm 6.6$ \\
\hline Oklahoma & $93.6 \pm 4.7$ & $80.4 \pm 7.2$ & $92.0 \pm 5.4$ & $84.0 \pm 6.6$ \\
\hline Oregon & $91.8 \pm 4.6$ & $80.7 \pm 6.8$ & $85.1 \pm 6.0$ & $76.4 \pm 7.3$ \\
\hline Pennsylvania & $94.8 \pm 2.4$ & $87.0 \pm 4.2$ & $92.0 \pm 3.3$ & $86.7 \pm 4.1$ \\
\hline Rhode Island & $98.4 \pm 2.0$ & $88.8 \pm 5.5$ & $94.6 \pm 3.7$ & $89.5 \pm 5.5$ \\
\hline South Carolina & $94.0 \pm 4.3$ & $85.1 \pm 6.3$ & $90.8 \pm 5.3$ & $81.8 \pm 7.1$ \\
\hline
\end{tabular}


320 Traditional Vaccine-Preventable Diseases and Potential Impact on the Otolaryngologist Greenlee, Newton

Table 1 (Continued)

\begin{tabular}{|c|c|c|c|c|c|}
\hline \multirow{2}{*}{ State } & \multirow[b]{2}{*}{ DTaP 3rd dose (\%) } & \multicolumn{4}{|l|}{$19-35$ months $^{50}$} \\
\hline & & DTaP 4th dose (\%) & \multicolumn{2}{|c|}{ MMR 1st dose (\%) } & Hib full series (\%) \\
\hline South Dakota & $98.5 \pm 2.1$ & $87.8 \pm 6.5$ & \multicolumn{2}{|c|}{$94.1 \pm 4.2$} & $89.0 \pm 5.9$ \\
\hline Tennessee & $96.6 \pm 2.4$ & $80.7 \pm 7.2$ & \multicolumn{2}{|c|}{$95.8 \pm 2.4$} & $80.5 \pm 7.1$ \\
\hline Texas & $93.1 \pm 2.9$ & $78.2 \pm 4.9$ & \multicolumn{2}{|c|}{$90.4 \pm 3.2$} & $76.2 \pm 4.9$ \\
\hline Utah & $90.7 \pm 4.9$ & $81.9 \pm 6.5$ & \multicolumn{2}{|c|}{$85.3 \pm 6.4$} & $78.8 \pm 6.9$ \\
\hline Vermont & $96.1 \pm 2.8$ & $86.1 \pm 5.4$ & \multicolumn{2}{|c|}{$93.2 \pm 3.4$} & $86.9 \pm 5.5$ \\
\hline Virginia & $91.5 \pm 5.8$ & $87.2 \pm 6.7$ & \multicolumn{2}{|c|}{$91.5 \pm 5.1$} & $87.5 \pm 6.3$ \\
\hline Washington & $93.0 \pm 4.8$ & $81.6 \pm 6.7$ & \multicolumn{2}{|c|}{$86.3 \pm 6.2$} & $75.6 \pm 7.5$ \\
\hline West Virginia & $92.1 \pm 5.0$ & $77.2 \pm 7.2$ & 88.9 & & $78.4 \pm 7.0$ \\
\hline Wisconsin & $94.9 \pm 3.4$ & $84.4 \pm 5.8$ & 93.2 & & $80.4 \pm 6.7$ \\
\hline Wyoming & $93.1 \pm 4.7$ & $72.8 \pm 8.7$ & 90.4 & & $75.1 \pm 8.2$ \\
\hline & & & & Kindergart & $n^{19}$ \\
\hline State & Varicella (\%) & Pneumococcal full s & $(\%)$ & $\mathrm{MMR}^{*}(\%)$ & $\mathrm{DTaP}^{*}(\%)$ \\
\hline US National & $91.0 \pm 0.9$ & $82.9 \pm 1.3$ & & $94.7^{* *}$ & $95^{* *}$ \\
\hline Alabama & $92.1 \pm 5.6$ & $84.3 \pm 7.3$ & & $\geq 93.5$ & $\geq 93.5$ \\
\hline Alaska & $88.4 \pm 4.7$ & $79.8 \pm 6.3$ & & 92.7 & 92.7 \\
\hline Arizona & $84.6 \pm 6.2$ & $79.8 \pm 6.7$ & & 94.2 & 94.3 \\
\hline Arkansas & $91.1 \pm 4.5$ & $78.9 \pm 7.0$ & & 88.4 & 85.6 \\
\hline California & $90.3 \pm 4.8$ & $84.1 \pm 6.1$ & & 92.6 & 92.4 \\
\hline Colorado & $87.9 \pm 5.1$ & $84.8 \pm 5.3$ & & 86.9 & 84.3 \\
\hline Connecticut & $93.1 \pm 4.5$ & $84.2 \pm 6.6$ & & 97 & 97 \\
\hline Delaware & $90.2 \pm 4.9$ & $85.9 \pm 5.8$ & & 97.8 & 97.7 \\
\hline Dist. of Columbia & $92.4 \pm 4.3$ & $84.3 \pm 6.3$ & & 90.4 & 90.2 \\
\hline Florida & $92.4 \pm 4.8$ & $81.6 \pm 8.0$ & & $\geq 93.3$ & $\geq 93.3$ \\
\hline Georgia & $94.5 \pm 3.8$ & $81.3 \pm 7.2$ & & $\geq 94.0$ & $\geq 94.0$ \\
\hline Hawaii & $90.0 \pm 4.4$ & $86.3 \pm 4.8$ & & NA & NA \\
\hline Idaho & $90.0 \pm 5.0$ & $83.6 \pm 6.2$ & & 89.5 & 89.4 \\
\hline Illinois & $92.8 \pm 2.6$ & $80.9 \pm 4.9$ & & 94.7 & 94.9 \\
\hline Indiana & $89.7 \pm 4.8$ & $80.1 \pm 6.2$ & & 89.3 & 92.7 \\
\hline lowa & $86.4 \pm 6.2$ & $84.2 \pm 6.6$ & & $\geq 91.9$ & $\geq 91.9$ \\
\hline Kansas & $95.0 \pm 3.3$ & $85.9 \pm 6.2$ & & 89.2 & 89.6 \\
\hline Kentucky & $92.4 \pm 4.4$ & $84.5 \pm 6.8$ & & 92.7 & 94.4 \\
\hline Louisiana & $91.4 \pm 4.1$ & $83.4 \pm 5.3$ & & 96.8 & 98.3 \\
\hline Maine & $94.5 \pm 2.8$ & $91.4 \pm 3.9$ & & 92.1 & 95.4 \\
\hline Maryland & $94.8 \pm 3.7$ & $87.5 \pm 6.2$ & & 99.1 & 99.6 \\
\hline Massachusetts & $93.6 \pm 3.9$ & $88.6 \pm 5.3$ & & 94.7 & 92.9 \\
\hline Michigan & $85.3 \pm 6.7$ & $74.4 \pm 8.1$ & & 94.3 & 95.1 \\
\hline Minnesota & $91.2 \pm 5.2$ & $86.3 \pm 6.8$ & & 93.5 & 93.7 \\
\hline Mississippi & $92.0 \pm 6.0$ & $82.8 \pm 7.4$ & & $\geq 99.2$ & $\geq 99.2$ \\
\hline Missouri & $89.8 \pm 4.7$ & $82.6 \pm 6.4$ & & 95.8 & 96 \\
\hline Montana & $90.9 \pm 4.8$ & $82.4 \pm 6.6$ & & 94.6 & 94.6 \\
\hline
\end{tabular}


Table 1 (Continued)

\begin{tabular}{|c|c|c|c|c|}
\hline \multirow[b]{2}{*}{ State } & \multirow[b]{2}{*}{ Varicella (\%) } & \multirow[b]{2}{*}{ Pneumococcal full series (\%) } & \multicolumn{2}{|c|}{ Kindergarten $^{19}$} \\
\hline & & & $\mathrm{MMR}^{*}(\%)$ & $\mathrm{DTaP}^{*}(\%)$ \\
\hline Nebraska & $95.1 \pm 3.2$ & $90.2 \pm 4.5$ & 96 & 96.4 \\
\hline Nevada & $89.7 \pm 4.3$ & $78.8 \pm 5.8$ & 94 & 93.2 \\
\hline New Hampshire & $94.5 \pm 2.9$ & $90.6 \pm 4.5$ & $\geq 91.4$ & $\geq 91.4$ \\
\hline New Jersey & $92.1 \pm 4.0$ & $84.5 \pm 5.8$ & $\geq 92.3$ & $\geq 92.3$ \\
\hline New Mexico & $92.4 \pm 4.0$ & $86.3 \pm 5.6$ & 97.7 & 96.4 \\
\hline New York & $91.7 \pm 3.2$ & $84.9 \pm 3.9$ & 98.2 & 97.5 \\
\hline North Carolina & $94.9 \pm 3.9$ & $87.2 \pm 6.1$ & 98.5 & 98.4 \\
\hline North Dakota & $92.2 \pm 4.1$ & $84.3 \pm 5.9$ & 89.8 & 89.6 \\
\hline Ohio & $92.9 \pm 3.6$ & $83.3 \pm 6.4$ & 91.9 & 92.2 \\
\hline Oklahoma & $92.2 \pm 5.1$ & $83.4 \pm 6.6$ & 90.3 & 90 \\
\hline Oregon & $83.3 \pm 6.2$ & $77.4 \pm 7.2$ & 94.1 & 93.8 \\
\hline Pennsylvania & $92.8 \pm 3.1$ & $87.5 \pm 3.9$ & 91.7 & NReg \\
\hline Rhode Island & $93.9 \pm 4.0$ & $88.9 \pm 5.3$ & 95.7 & 96.1 \\
\hline South Carolina & $91.5 \pm 5.0$ & $81.6 \pm 7.2$ & 96.5 & 97.2 \\
\hline South Dakota & $92.6 \pm 4.4$ & $87.2 \pm 6.8$ & 97.1 & 97.2 \\
\hline Tennessee & $92.4 \pm 4.0$ & $85.5 \pm 6.1$ & $\geq 95.1$ & $\geq 95.1$ \\
\hline Texas & $89.9 \pm 3.3$ & $78.6 \pm 4.7$ & 97.4 & 97.2 \\
\hline Utah & $86.3 \pm 6.0$ & $80.0 \pm 6.9$ & 94 & 93.8 \\
\hline Vermont & $87.0 \pm 4.6$ & $86.1 \pm 5.3$ & 92.7 & 93.2 \\
\hline Virginia & $92.2 \pm 4.7$ & $83.2 \pm 7.6$ & 93.4 & 97.4 \\
\hline Washington & $86.7 \pm 5.8$ & $79.5 \pm 6.9$ & 89.4 & 90.7 \\
\hline West Virginia & $87.1 \pm 5.5$ & $77.7 \pm 7.0$ & 97.6 & 97.6 \\
\hline Wisconsin & $91.7 \pm 4.1$ & $86.4 \pm 5.2$ & 91.6 & 96.5 \\
\hline Wyoming & $86.4 \pm 6.3$ & $80.3 \pm 7.2$ & 96.8 & 96.7 \\
\hline
\end{tabular}

Abbreviations: DTaP, diphtheria, tetanus and pertussis; Hib, haemophilus influenzae type b; MMR, measles-mumps-rubella; NA, not available; NReg, no registry.

*Kindergartners were considered up to date if they received all doses required for school entry in their jurisdiction.

${ }^{* *}$ National Median.

in DTaP, with Ecuador (83\%), Panama (80\%), Venezuela (78\%), Guatemala (73\%), and Haiti (48\%) reporting the lowest rates.

In the European region (-Table 2), countries reporting DTaP (three doses) rates below $85 \%$ were: Austria (83\%), San Marino (80\%) and Ukraine (76\%). Countries with MCV (two doses) rates below 85\% were: Denmark (84\%), Greece (83\%), San Marino (76\%), France (74\%), Austria (64\%) and Ukraine (54\%). Countries reporting $\mathrm{Hib}$ (three doses) below 85\% were: Austria (83\%), Bulgaria (83\%), Ukraine (83\%), San Marino (79\%), Bosnia and Herzegovina (79\%), Russian Federation (31\%) and Belarus (20\%).

Regional vaccination rate data from the Eastern Mediterranean, Africa, Southeast Asia and West Pacific regions are also summarized in - Table 2 . Individual country vaccination rates data can be found on the WHO website. ${ }^{11}$

\section{Global and U.S. Reported Disease Incidence}

Global VPD incidence data represent official figures reported to WHO/UNICEF through the Joint Reporting Form for 2014, and was last updated in January of 2016. WHO/UNICEF region incidence data are summarized in -Table 3 and the U.S. incidence data for 2005-2014, 2000 and 1995 are displayed in - Table 4. WHO/UNICEF reports that there were 7,324 reported cases of diphtheria in 2014, worldwide; this number increased significantly from 2013. According to the most recent data, there have been only two cases $(2012,2014)$ of diphtheria in the U.S. over the past 10 years. Diphtheria cases appear to be heavily concentrated in India (6094 cases) and Nepal (1079).

In 2014 , there were 267,582 reported cases of measles worldwide, and 667 cases in the U.S. The reported cases of measles were highest in Africa and Asia, with the greatest 
322 Traditional Vaccine-Preventable Diseases and Potential Impact on the Otolaryngologist Greenlee, Newton

Table 2 World Health Organization regional average estimated vaccination coverage for $2014^{51}$

\begin{tabular}{|l|l|l|l|}
\hline & & Vaccine & \\
\hline WHO Region & DTaP 3rd dose (\%) & MCV 2nd dose (\%) & Hib 3rd dose (\%) \\
\hline African & 77 & 11 & 77 \\
\hline Americas & 90 & 51 & 90 \\
\hline Eastern Mediterranean & 82 & 66 & 72 \\
\hline European & 95 & 84 & 85 \\
\hline South East Asia & 84 & 59 & 30 \\
\hline Western Pacific & 96 & 93 & 21 \\
\hline Global & 86 & 56 & 56 \\
\hline
\end{tabular}

Abbreviations: DTP, diphtheria, tetanus and pertussis; Hib, haemophilus influenzae type b; MCV, meningococcal vaccine.

Table 3 World Health Organization 2014 regional vaccine-preventable disease incidence data ${ }^{34}$

\begin{tabular}{|l|l|l|l|l|}
\hline & Disease & Rubella \\
\hline WHO Region & Diphtheria & Measles & Mumps & (402 \\
\hline African & 1 & 73914 & 7 & 10 \\
\hline Americas & 9 & 1966 & 15643 & 2945 \\
\hline Eastern Mediterranean & 40 & 18080 & 9608 & 653 \\
\hline European & 35 & 14176 & 10807 & 9263 \\
\hline South East Asia & 7217 & 28403 & 34623 & 12814 \\
\hline Western Pacific & 22 & 131043 & 234473 & 33087 \\
\hline Global & 7324 & 267582 & 305161 & \\
\hline
\end{tabular}

Table 4 Annual US national vaccine reportable disease incidence from the CDC's Summary of Notifiable Diseases reports

\begin{tabular}{|c|c|c|c|c|c|}
\hline \multirow[b]{2}{*}{ Year } & \multicolumn{5}{|c|}{ Vaccine-Preventable Diseases Incidence } \\
\hline & Diphtheria & Measles & Mumps & Rubella & Haemophilus Type $\mathbf{B}^{*}$ \\
\hline $2014^{8}$ & 1 & 667 & 574 & 2 & 40 \\
\hline $2013^{8}$ & 0 & 187 & 584 & 9 & 31 \\
\hline $2012^{8}$ & 1 & 55 & 229 & 9 & 30 \\
\hline $2011^{8}$ & 0 & 212 & 370 & 4 & 14 \\
\hline $2010^{8}$ & 0 & 63 & 2612 & 5 & 23 \\
\hline $2009^{52}$ & 0 & 71 & 1991 & 3 & 38 \\
\hline $2008^{53}$ & 0 & 140 & 454 & 16 & 30 \\
\hline $2007^{54}$ & 0 & 43 & 800 & 11 & 22 \\
\hline $2006^{55}$ & 0 & 55 & 6584 & 11 & 29 \\
\hline $2005^{56}$ & 0 & 66 & 314 & 11 & 9 \\
\hline $2000^{57}$ & 1 & 86 & 338 & 176 & $\mathrm{NA}^{* *}$ \\
\hline $1995^{58}$ & 0 & 309 & 906 & 128 & $N A^{* *}$ \\
\hline
\end{tabular}

Abbreviation: NA, not available.

* The National Notifiable Diseases Surveillance System (NNDSS) only requires Haemophilus serotype reporting in those $<5$ years of age

** Serotype reporting not required in 2000 or 1995 
Table 5 Estimated percentage of children enrolled in kindergarten in the US with medical and nonmedical vaccination exemptions by state for the $2014-15$ school year ${ }^{19}$

\begin{tabular}{|c|c|c|}
\hline \multirow[t]{2}{*}{ State } & \multicolumn{2}{|c|}{ Kindergarten Exemption Rates } \\
\hline & Medical (\%) & Nonmedical (\%) \\
\hline US National Median & 0.2 & 1.5 \\
\hline Alabama & 0.1 & 0.7 \\
\hline Alaska & 1.3 & 4.5 \\
\hline Arizona & 0.1 & 4.6 \\
\hline Arkansas & $<0.1$ & 1.2 \\
\hline California & 0.2 & 2.5 \\
\hline Colorado & $<0.1$ & 5.4 \\
\hline Connecticut & 0.3 & 1.6 \\
\hline Delaware & 0.4 & 0.9 \\
\hline Dist. of Columbia & 0.6 & 0.5 \\
\hline Florida & 0.3 & 1.8 \\
\hline Georgia & 0.1 & 2.0 \\
\hline Hawaii & $<0.1$ & 3.3 \\
\hline Idaho & 0.3 & 6.2 \\
\hline Illinois & NA & NA \\
\hline Indiana & 0.5 & 0.8 \\
\hline lowa & 0.3 & 1.4 \\
\hline Kansas & 0.3 & 1.1 \\
\hline Kentucky & 0.2 & 0.7 \\
\hline Louisiana & 0.1 & 0.6 \\
\hline Maine & 0.5 & 3.9 \\
\hline Maryland & 0.4 & 0.8 \\
\hline Massachusetts & 0.3 & 1.1 \\
\hline Michigan & 0.3 & 5.0 \\
\hline Minnesota & NA & NA \\
\hline Mississippi & $<0.1$ & NA \\
\hline Missouri & NA & NA \\
\hline Montana & 0.3 & 3.6 \\
\hline Nebraska & 0.6 & 1.1 \\
\hline Nevada & 0.3 & 1.1 \\
\hline New Hampshire & 0.2 & 2.7 \\
\hline New Jersey & 0.2 & 1.6 \\
\hline New Mexico & 0.1 & 1.2 \\
\hline New York & 0.1 & 0.7 \\
\hline North Carolina & 0.1 & 0.9 \\
\hline North Dakota & 0.3 & 2.4 \\
\hline Ohio & 0.3 & 1.8 \\
\hline Oklahoma & 0.1 & 1.4 \\
\hline Oregon & 0.2 & 5.8 \\
\hline Pennsylvania & 0.3 & 1.8 \\
\hline Rhode Island & 0.2 & 0.9 \\
\hline
\end{tabular}

(Continued)
Table 5 (Continued)

\begin{tabular}{|l|l|l|}
\hline South Carolina & 0.1 & 1.0 \\
\hline South Dakota & 0.2 & 1.5 \\
\hline Tennessee & 0.2 & 0.9 \\
\hline Texas & NA & 1.3 \\
\hline Utah & 0.2 & 4.1 \\
\hline Vermont & 0.2 & 5.9 \\
\hline Virginia & 0.3 & 0.8 \\
\hline Washington & 1.2 & 3.5 \\
\hline West Virginia & 0.2 & NA \\
\hline Wisconsin & 0.4 & 4.9 \\
\hline Wyoming & NA & NA \\
\hline
\end{tabular}

Abbreviation: NA, not available.

number of cases occurring in the Philippines $(58,848)$, China $(52,628)$, the Democratic Republic of the Congo $(33,711)$, India $(24,977)$, Vietnam $(15,033)$, Ethiopia $(12,739)$, Angola $(11,699)$ and Somalia $(10,229)$. There were 21 countries that had over 1,000 reported cases.

Mumps cases worldwide in 2014 were noted to be 305,161 , with 574 occurring in the U.S. The greatest incidence was reported in China (187,500), Japan (46,340), Nepal $(34,034)$, Egypt $(7,626)$, Colombia $(7,368)$, Mexico $(4,143)$ and the United Kingdom $(2,958)$.

Worldwide, there were 33,087 reported cases of rubella, and two cases in the U.S. The countries with the highest reported cases were China $(11,793)$, India $(4,870)$ and Indonesia $(3,267)$.

Specific country-level reported disease incidence data can be found on the WHO website. ${ }^{12}$

\section{Discussion}

The recent outbreaks of measles in California, and of mumps at numerous college campuses in 2015 serve as a reminder that even countries with relatively high vaccination rates remain at risk for future outbreaks. Despite the elimination of endemic measles from the U.S. in $2000,{ }^{13} 2014$ saw the highest levels of measles cases over the past two decades. While this incidence increase has several likely contributing factors, it has brought an alarming trend of vaccine avoidance and exemption to the national spotlight.

Parental concerns about vaccine safety have increased over the past 15 years, and more parents are choosing to seek alternative vaccination plans or forgo vaccination altogether. ${ }^{14}$ All 50 states have a set of vaccination requirements that children must meet before enrollment in school. Because laws regarding vaccination are determined at a state level, regulations differ from state to state. All states allow for medical exemptions when vaccinations are medically contraindicated and all but three states, Mississippi, West Virginia and California, allow some form of NME. ${ }^{15,16}$ As of October of 2016, 47 states allow for a religious exemption, while only 18 


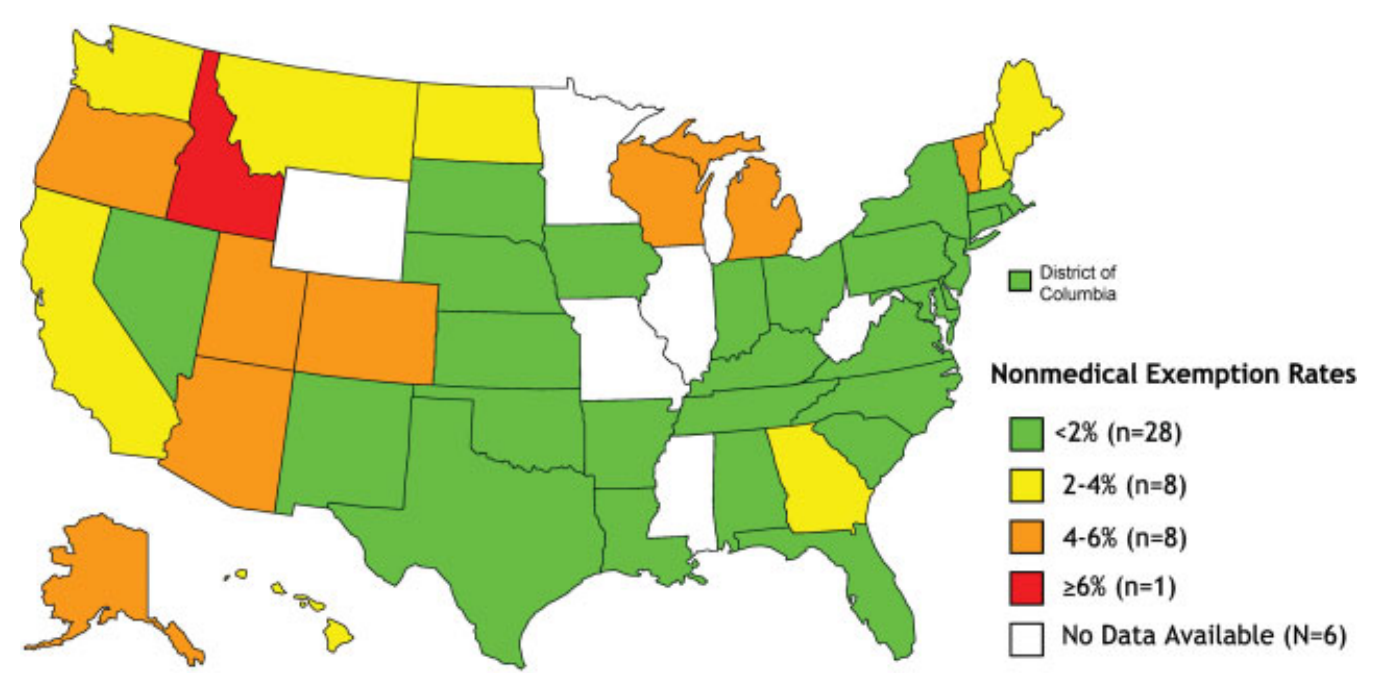

Fig. 1 Estimated percentage of children enrolled in kindergarten in each state that obtained a nonmedical exemption from receiving one or more vaccines in the United States for the 2014-2015 school year.

allow for a philosophical exemption. ${ }^{17}$ An increasing amount of literature has been published in recent years in an attempt to quantify and understand trends in NMEs. On a national level, NMEs have shown a general increase over the last decade, with states such as Arkansas, California and Oregon tripling their NME rate between 2005 and 2013. ${ }^{18}$ Kindergarten vaccine exemption rates are compiled yearly using CDC data and are summarized in - Table 5 and presented in - Fig. 1. The data show that while the national median NME rate is only 1.7, states such as Idaho, Vermont, Oregon and Colorado have NME rates of over $5.0 \%{ }^{19}$ This regional disparity is backed by several sources that identify the clustering of exemptions across state and even county lines. ${ }^{20-22}$ When communities of any size experience higher clusters of NMEs and lower vaccination rates, herd immunity can be compromised and the risk of VPD outbreaks can increase. Herd immunity relies on the reduction of susceptible persons in the population and works to reduce the efficiency with which a microbe is transmitted from one person to another. When there are enough immune individuals to stop effective transmission, outbreaks no longer occur. Several studies have shown a strong association between small regional clusters of NMEs and higher risks of pertussis and measles outbreaks. ${ }^{23,24}$ Increased attention to the effects of NMEs on preventable disease incidence is necessary to better explain these changes and their effects on public health.
A subset of the literature attempts to explain the increasing trend in NMEs. Traditionally, under-vaccination was associated with lower access to health care and it was more prevalent among the impoverished, inner city ethnic and racial minorities, and those with a lower level of education. ${ }^{25,26}$ However, increasingly, under-vaccination is resulting from higher NME rates reported among white, highly educated and wealthier populations..$^{20,27,28}$ The most prevalent concerns voiced by parents are associated with vaccine safety and common themes include the potential for adverse reactions, developmental problems, dangerous vaccine ingredients and the need for too many shots at one time under the national guidelines. ${ }^{18,29,30}$ Other sources have mentioned an inverse relationship between the difficulty of receiving an exemption and NME levels, ${ }^{15}$ and an additional analysis shows a greater increase in NMEs in states where both religious and philosophical exemptions are allowed. ${ }^{10}$ It is clear that legislation can have an impact on vaccination rates.

Families who choose to not vaccinate or intentionally under-vaccinate their children rely on herd immunity to protect their children from VPDs. For herd immunity to be established, there must be enough protected individuals in a population to exceed the herd immunity threshold, which is defined as the fraction of a population that must be immune to confer herd immunity on those not protected from a disease.

Table 6 Estimated herd immunity thresholds and critical vaccination coverage using generally accepted reproductive numbers for common vaccine-preventable diseases

\begin{tabular}{|l|l|l|l|}
\hline Vaccine-Preventable Disease & $\mathbf{R}_{\mathbf{0}}{ }^{* 59,60}$ & ${\text { Herd Immunity Threshold }(\%)^{31}}$ Critical Vaccination Coverage $^{* *}$ (\%) $^{31}$ \\
\hline Diphtheria & 4 to 5 & $75-80$ & $79-84$ \\
\hline Measles & 11 to 18 & $91-94$ & $96-99$ \\
\hline Mumps & 7 to 14 & $86-93$ & 90 to 98 \\
\hline Rubella & 6 to 14 & $83-94$ & 87 to 99 \\
\hline
\end{tabular}

${ }^{*} R_{0}$ values indicate the number of individuals that can be directly infected by one infectious case. Herd immunity thresholds are a function of this value.

**herd immunity thresholds are adjusted to account for vaccine effectiveness. 
An important objective of the public health departments is to meet vaccination rate goals that are likely to ensure herd immunity. Although critical vaccination coverage values have been identified for common VPDs, it is important to note that the heterogeneity of populations, vaccine effectiveness and virus strain reproductive numbers $\left(R_{0}\right)$ cause significant variation in the critical vaccination coverage values over time and in different populations. ${ }^{31}$ Ranges of some of the more accepted herd immunity thresholds and critical vaccination rates can be seen in - Table 6. Based on the CDC's estimated vaccination rate data for 19-35-month-olds, there are currently 19 states that are right at or below the lower bound of estimated herd immunity threshold for measles (91\%). There are also nine states that are at or below estimated herd immunity thresholds based on the CDC's kindergarten data. While this type of analysis is useful in determining trends, both datasets are estimates based on telephone and immunization program surveys and reporting/sampling bias could be a factor in overestimating rates.

In most cases, the sources of U.S. outbreaks have been linked to international travel and immigration. This is especially true in the case of measles. A recent MMWR report looking at measles cases in the first half of 2014 indicated that $97 \%$ of 288 cases were associated with importation from 18 countries. ${ }^{32}$ Forty-five of these cases were reported to be direct importation and half were travelers returning from the Philippines, where a large outbreak was occurring. Of those who became infected, $69 \%$ were unvaccinated and $20 \%$ had an unknown vaccination status. The remaining importations were spread relatively evenly amongst the WHO world regions. A similar analysis was performed on the 911 confirmed cases of measles in the U.S. between 2001 and $2011 .^{33}$ A total of 801 (88\%) of these cases were determined to be importassociated from a total of 57 countries. China, Japan, India, Italy, the Philippines and the U.K. were all shown to be associated with 20 or more of these imported cases. Unsurprisingly, the Philippines, China and India were countries reporting a high incidence of measles in $2014 .^{34}$

In an increasingly interconnected world, the chances for exposure to infectious diseases grow and vaccination rates in developed and developing countries directly affect each other. An estimated 1.9 million U.S. children travel overseas each year, often to countries where these diseases are still endemic. ${ }^{35}$ It is highly recommended that parents consult their physicians about vaccination recommendations before taking children abroad. In some cases, it is even recommended that children receive vaccines ahead of schedule to protect them from exposure abroad. ${ }^{36}$

\section{Disease Presentation and Clinical Guidelines}

Many of these commonly vaccinated diseases have not been seen in the U.S. in large numbers and, therefore, are unlikely to have been encountered during physician training or practice. With the possibility of encountering these diseases both at home and abroad and the likelihood of head and neck presentations, the following review of clinical presentations and treatment guidelines will serve as a guide to VPDs that may present to the otolaryngologist.

\section{Measles $^{37,38}$}

Measles is an acute viral infection characterized by the prodrome of fever (as high as 105), malaise, cough, coryza and conjunctivitis followed by a maculopapular rash. The rash starts $\sim 14$ days after exposure, starts on the head and spreads to the trunk and extremities. Measles can result in complications such as pneumonia, encephalitis and death, with a death rate of $2-3 / 1000$.

The average incubation period is 14 days with a range of 7-21 days. Patients are considered infectious from 4 days before to 4 days after the onset of the rash. Laboratory testing is required for all suspected cases of measles and includes measles-specific immunoglobulin $\mathrm{M}(\operatorname{IgM})$ antibodies and measles ribonucleic acid (RNA) detection by real-time polymerase chain reaction (RT-PCR). These samples are obtained via a serum sample and throat swab. Virus isolation and RNA detection are much more likely to be successful early in the infection (first 3 days of rash) but may be successfully isolated up to 10 days after the start of the rash.

Patients should be isolated for 4 days post rash onset. Airborne precautions should be instituted in a hospital setting. Measles, mumps and rubella (MMR) vaccine, if administered within 72 hours of initial measles exposure, and immunoglobulin (IG), if administered within 6 days of exposure, may provide some protection or modify the clinical course of the disease. Individuals who are at high risk for severe disease and complications from measles (infants aged $<12$ months, pregnant women without evidence of measles immunity and severely immunocompromised persons) should receive IG.

Children who are malnourished are at a much higher risk of severe complications. In the developing world, this population has a death rate as high as $10 \%$. The WHO recommends two doses of vitamin A (separated by 24 hours) to infected children in the developing world. This has been shown to not only reduce blindness but it can also cut the death rate by $50 \%$.

\section{Mumps $^{39,40}$}

Mumps is an acute viral illness caused by a paramyxovirus. The classic symptom of mumps is parotitis lasting at least 2 days and it may persist for longer than 10 days. The parotitis typically develops 16 to 18 days after exposure and is present in $31-65 \%$ of cases. Non-specific symptoms may precede the parotitis by a few days, including low-grade fever, myalgia, anorexia, malaise and headache. Mumps may also present as a nonspecific respiratory infection or subclinical infection. Fifty percent of individuals with mumps have cerebrospinal fluid pleocytosis, but fewer than $10 \%$ have symptoms of central nervous system infection.

In the pre-vaccine era, unilateral deafness caused by mumps occurred in 1 in 20,000 infected individuals and orcheitis presented in 11.6-66\% of infected post-pubertal males. The virus is known to cross the placenta but has not been associated with any known congenital defects. 
Mumps viral count is highest around the time of onset of parotitis and decreases rapidly after that. Most transmission likely occurs before and within 5 days of parotitis onset.

If mumps is suspected, laboratory tests should be performed. Acute mumps infection can be detected with serum levels of IgM (enzyme immunoassay is preferred over immunofluorescence assay), a significant rise in immunoglobulin $\mathrm{G}(\operatorname{IgG})$ titers, positive mumps viral culture or detection of the virus by RT-PCR. Parotid duct swab yields the best sample, especially when the gland area is massaged for 30 seconds prior to collection. Samples should be collected as close to the onset of parotitis as possible.

There are currently no medications that have been shown to treat the mumps virus. Treatment is focused on relieving symptoms and preventing its spread. This includes pain control, hydration, warm or cold compresses to the parotid region, soft diet and isolation for 5 days.

\section{Rubella ${ }^{41,42}$}

Rubella is caused by the Rubivirus and is characterized by a generalized erythematous maculopapular rash. Children usually develop no constitutional symptoms but adults may experience headaches, malaise, mild coryza and conjunctivitis. Postauricular, occipital and posterior cervical lymphadenopathy is characteristic and precedes the rash by $5-10$ days. The transient polyarthralgia is rarely present in children but is more common in adolescents and adults. Encephalitis and thrombocytopenia are rare complications. Congenital rubella has much more common and severe complications including miscarriage, fetal death and congenital anomalies. The classical presentation of congenital rubella includes ophthalmologic issues, cardiac defects, sensorineural hearing loss, and neurological issues. Mild forms of the disease may be associated with few obvious abnormalities but more outward presentations include purpuric skin lesions (blueberry muffin appearance), thrombocytopenia, hepatosplenomegaly and radiolucent bones. The severity of these anomalies is often associated with the gestational age at onset of infection, with a much higher rate of a clinically significant effect in infants infected in the first 4 weeks of gestation.

Maximal contamination period is from a few days before to 7 days after the presentation of the rash. A small number of infants with congenital rubella may shed the virus for up to a year in their nasopharyngeal secretions and urine. The incubation period for postnatal infection is from 14 to 23 days.

The clinical diagnosis of rubella is unreliable; therefore, cases must be confirmed by laboratory testing. The rubella virus can be detected from nasal, throat, blood, urine and cerebrospinal fluid (CSF) specimens. Throat swabs and urine sample collected for RT-PCR are recommended. Cerebrospinal fluid testing should be reserved for patient suspected to have rubella encephalitis. Enzyme immunoassays (EIAs) can be used to detect $\operatorname{IgG}$ and IgM antibodies. This test is sensitive and relatively easy to perform. Because this disease is rare in the U.S., a high proportion of IgM-positive tests will be false positives.

Patients with rubella should be isolated for 7 days after rash onset. All persons who are at risk and cannot provide evidence of vaccination should be revaccinated. There is no effective antiviral treatment for rubella. Immunoglobulins are sometimes used in pregnant women who have been exposed.

\section{Diphtheria $^{43,44}$}

Diphtheria is caused by the toxigenic strains of gram-positive Corynebacterium diptheriae. Diphtheria typically presents with a sore throat, difficulty swallowing, malaise and lowgrade fever. The hallmark of respiratory diphtheria is the gray-whitish pseudomembrane over the tonsils, pharynx or larynx that bleeds when removed. Swelling of the cervical lymph nodes gives rise to a "bull-neck" appearance. As the pseudomembrane extends from the pharynx to the larynx, it may cause obstruction of the airway and if left untreated may be fatal with a case fatality rate of $10 \%$. Diphtheria toxin can also cause systemic complications with damage to the myocardium, nervous system and kidneys. Cutaneous diphtheria is usually mild, typically consisting of non-distinctive sores or shallow ulcers and it rarely causes toxic effects $(1-2 \%)$.

Diagnostic tests used to confirm diphtheria include isolation of the bacteria in culture and toxigenicity testing. There are no other commercially available tests but the CDC can perform polymerase chain reaction (PCR) tests on clinical specimens. Clinical specimens for culture should be taken from the nose or nasopharynx and throat from all persons with suspected cases and those in close contact with them. Material should be taken from the pseudomembrane or the area just below the pseudomembrane. Toxigenicity testing using the Elek test should be done to determine whether the organisms produce diphtheria toxin.

The mainstay of treatment is prompt administration of diphtheria antitoxin in suspected cases, even before laboratory confirmation. The amount of antitoxin used depends on the extent of the disease. To obtain the antitoxin, the clinician should contact the CDC Emergency Operations Center (770488-7100). In addition, the patient should receive antibiotics with erythromycin or penicillin administered as a 14-day course. Droplet precautions are recommended until two nasal and pharyngeal cultures are negative.

\section{Haemophilus influenzae Infection ${ }^{45,46}$}

Haemophilus Influenzae (H. influenzae) is an invasive disease caused by the gram-negative coccobacillus bacterium haemophilus influenzae. The bacteria may either be encapsulated (types a-f) or non-encapsulated (non-typeable). Invasive $H$. influenzae may cause meningitis, bacteremia or sepsis, epiglottitis, pneumonia, septic arthritis, osteomyelitis, pericarditis and cellulitis. Before effective vaccination, Hib was the cause of more than $95 \%$ of all invasive haemophilus infections. Meningitis occurred in more than two thirds of the cases of Hib disease with resulting hearing impairment or severe permanent neurological sequelae, paralysis in $15-30 \%$ of survivors and $4 \%$ of all cases were fatal.

Gram stain of infected fluid may demonstrate small gram-negative coccobacilli suggestive of invasive haemophilus disease and positive culture establishes the diagnosis. All isolates of $H$. influenzae should be serotyped. Antigen 
testing of body fluid may be performed in addition to cultures in those patients who have received antimicrobial therapy.

Treatment includes either a third-generation cephalosporin (cefotaxime or ceftriaxone) or chloramphenicol in combination with ampicillin. Ampicillin-resistant strains of Hib are now common, so Ampicillin should not be used as a monotherapy. Patients showing signs of airway obstruction should be given supplemental oxygen and taken to the operating room (OR) for management of the airway according to the local hospital's epiglottitis protocol.

\section{Final Comments}

The recent rise in NMEs in school-age children has led to a higher risk of VPD occurrence. This trend coincides with an increase in the severity and risk of outbreaks within the U.S. Increasing global mobility allows for ease of disease transmission and limits the extent to which outbreaks can be contained. Most otolaryngologists have not cared for patients with these diseases and this paper serves as a review of the clinical presentations and treatment guidelines for these VPDs.

Due to the increased chance of exposure to patients with VPDs and their presentation in the head and neck, it is recommended that otolaryngologists familiarize themselves with these disease processes, their treatment, and the agencies involved in reporting occurrences. Each state and country maintains its own set of reportable diseases and mandates reporting to the respective department of health. Physicians should familiarize themselves with reportable diseases in their state of practice and identify the forms necessary for notification. The VPDs discussed in this article are included on most state's reportable disease lists.

The misconception is often that these diseases only present in young unvaccinated children. The recent 2015 measles outbreak in California showed that $40 \%$ of the intentionally unvaccinated patients who contracted measles were adults. ${ }^{47}$ Similarly, recent outbreaks of mumps in college campuses are primarily affecting students in their late teens and early twenties. However, certain VPDs are more likely to present in early childhood. Children under the age of 18 comprise 30$35 \%$ of the patient population of general otolaryngologists and most children receiving otolaryngologic care in the US receive care from a general otolaryngologist. ${ }^{48}$

While the likelihood that an individual otolaryngologist will see one of these VPDs is small, as global mobility increases and social changes affect the number of patients choosing not to vaccinate, exposure may increase with time. With this increased likelihood of exposure, otolaryngologists need to be aware of the variable presentations of these diseases and include them in their differential diagnosis where appropriate.

While the majority of work otolaryngologists perform is in the diagnosis and management of diseases of the head and neck, they do play a role in disease prevention by recommending vaccinations. Otolaryngologists often recommend immunization for influenza to prevent recurrent ear and sinus infections in susceptible populations. They also recommend pneumococcal vaccinations to prevent increased risk of meningitis in patients undergoing cochlear implantation. More recently, otolaryngologists are playing a larger role in recommending HPV vaccines to prevent oropharyngeal cancer. Data consistently suggests that the more patients and families are encouraged to vaccinate, the more likely they are to actually undergo vaccinations. ${ }^{49}$ As part of the medical community, otolaryngologists who treat children and adults should encourage routine vaccinations.

\section{Financial Disclosure}

The authors have no financial relationships relevant to this manuscript.

\section{Conflict of Interest}

None

\section{References}

1 Roush SW, Murphy TV; Vaccine-Preventable Disease Table Working Group. Historical comparisons of morbidity and mortality for vaccine-preventable diseases in the United States. JAMA 2007; 298(18):2155-2163

2 Fine PE. Herd immunity: history, theory, practice. Epidemiol Rev 1993;15(02):265-302

3 Fine P, Eames K, Heymann DL. "Herd immunity": a rough guide. Clin Infect Dis 2011;52(07):911-916

4 Centers for Disease Control and Prevention (CDC). Absence of transmission of the $\mathrm{d} 9$ measles virus-Region of the Americas, November 2002-March 2003. MMWR Morb Mortal Wkly Rep 2003;52(11):228-229

5 Pan American Health Organization. Americas region is declared the world's first to eliminate rubella. Pan American Health Organization website. http://www.paho.org/hq/index.php?option=com_content \&view=article\&id=10798\&Itemid=1926\&lan$\mathrm{g}=\mathrm{en}$. April 29, 2015. Accessed May 11, 2015

6 Strebel PM, Papania MJ, Dayan GH, Haalsey NA. Measles vaccine. In: Plotkin S, Orenstein W, Offit P, ed. Vaccines. 5th ed. Philadelphia, PA: Elsevier; 2008:353-398

7 Rubella. In: Atkinson W, Wolfe S, Hamborksy J, McIntyre L, Eds. Epidemiology and prevention of vaccine-preventable diseases, Washington DC: Public Health Foundation; 2009:157-176

8 Centers for Disease Control and Prevention. Morbidity and Mortality Weekly Report. Notifiable Diseases and Mortality Tables February 19, 2016. Available at the Centers for Disease Control and Prevention Website. http://www.cdc.gov/mmwr/volumes/ 65/wr/pdfs/mm6506md.pdf. February 13, 2016. Accessed February 18,2016

9 Chen RT, Hibbs B. Vaccine safety: current and future challenges. Pediatr Ann 1998;27(07):445-455

10 Omer SB, Richards JL, Ward M, Bednarczyk RA. Vaccination policies and rates of exemption from immunization, 20052011. N Engl J Med 2012;367(12):1170-1171

11 World Health Organization. Baccille Calmette Guérin vaccine. WHO vaccine-preventable diseases: monitoring system 2015 global summary. http://apps.who.int/immunization_monitoring/globalsummary/timeseries/tscoveragebcg.html. Accessed March 10 $0^{\text {th }}, 2015$

12 World Health Organization. Diphtheria reported cases. WHO vaccine-preventable diseases: monitoring system 2015 global summary. http://apps.who.int/immunization_monitoring/globalsummary/timeseries/tsincidencediphtheria.html. Accessed March $10^{\text {th }} 2015$ 
13 Katz SL, Hinman AR. Summary and conclusions: measles elimination meeting, 16-17 March 2000. J Infect Dis 2004;189 (Suppl 1):S43-S47

14 Omer SB, Salmon DA, Orenstein WA, deHart MP, Halsey N. Vaccine refusal, mandatory immunization, and the risks of vaccine-preventable diseases. N Engl J Med 2009;360(19):1981-1988

15 Blank NR, Caplan AL, Constable C. Exempting schoolchildren from immunizations: states with few barriers had highest rates of nonmedical exemptions. Health Aff (Millwood) 2013;32(07): 1282-1290

16 McNutt LA, Desemone C, DeNicola E, et al. Affluence as a predictor of vaccine refusal and underimmunization in California private kindergartens. Vaccine 2016;34(14):1733-1738

17 National Conference of State Legisliatures. States with religious and philosophical exemptions from school immunization requirements, 2016. Available at: http://www.ncsl.org/research/health/school-immunization-exemption-state-laws.aspx. Accessed March 17, 2017

18 Wang E, Clymer J, Davis-Hayes C, Buttenheim A. Nonmedical exemptions from school immunization requirements: a systematic review. Am J Public Health 2014;104(11):e62-e84

19 Centers for Disease Control and Prevention. Vaccination coverage among children in kindergarten- United States,2014-15 school year. MMWR Morb Mortal Wkly Rep 2015;64(33):913-920

20 Richards JL, Wagenaar BH, Van Otterloo J, et al. Nonmedical exemptions to immunization requirements in California: a 16-year longitudinal analysis of trends and associated community factors. Vaccine 2013;31(29):3009-3013

21 Omer SB, Enger KS, Moulton LH, Halsey NA, Stokley S, Salmon DA. Geographic clustering of nonmedical exemptions to school immunization requirements and associations with geographic clustering of pertussis. Am J Epidemiol 2008;168(12): 1389-1396

22 Imdad A, Tserenpuntsag B, Blog DS, Halsey NA, Easton DE, Shaw J. Religious exemptions for immunization and risk of pertussis in New York State, 2000-2011. Pediatrics 2013;132(01):37-43

23 Atwell JE, Van Otterloo J, Zipprich J, et al. Nonmedical vaccine exemptions and pertussis in California, 2010. Pediatrics 2013;132 (04):624-630

24 Feikin DR, Lezotte DC, Hamman RF, Salmon DA, Chen RT, Hoffman RE. Individual and community risks of measles and pertussis associated with personal exemptions to immunization. JAMA 2000;284(24):3145-3150

25 Wood D, Donald-Sherbourne C, Halfon N, et al. Factors related to immunization status among inner-city Latino and African-American preschoolers. Pediatrics 1995;96(2 Pt 1):295-301

26 Luman ET, McCauley MM, Shefer A, Chu SY. Maternal characteristics associated with vaccination of young children. Pediatrics 2003;111(5 Pt 2, S1)1215-1218

27 Smith PJ, Chu SY, Barker LE. Children who have received no vaccines: who are they and where do they live? Pediatrics 2004;114(01):187-195

28 Birnbaum MS, Jacobs ET, Ralston-King J, Ernst KC. Correlates of high vaccination exemption rates among kindergartens. Vaccine 2013;31(05):750-756

29 Gust DA, Strine TW, Maurice E, et al. Underimmunization among children: effects of vaccine safety concerns on immunization status. Pediatrics 2004;114(01):e16-e22

30 Bardenheier B, Yusuf H, Schwartz B, Gust D, Barker L, Rodewald L. Are parental vaccine safety concerns associated with receipt of measles-mumps-rubella, diphtheria and tetanus toxoids with acellular pertussis, or hepatitis B vaccines by children? Arch Pediatr Adolesc Med 2004;158(06):569-575

31 Plans-Rubió P. Evaluation of the establishment of herd immunity in the population by means of serological surveys and vaccination coverage. Hum Vaccin Immunother 2012;8(02):184-188

32 Gastañaduy PA, Redd SB, Fiebelkorn AP, et al; Division of Viral Disease, National Center for Immunization and Respiratory Dis- eases, CDC. Measles - United States, January 1-May 23, 2014 MMWR Morb Mortal Wkly Rep 2014;63(22):496-499

33 Papania MJ, Wallace GS, Rota PA, et al. Elimination of endemic measles, rubella, and congenital rubella syndrome from the Western hemisphere: the US experience. JAMA Pediatr 2014; 168(02):148-155

34 World Health Organization. Country reported disease incidence time series. http://apps.who.int/immunization_monitoring/globalsummary/timeseries/tsincidencediphtheria.html. Accessed February $1^{\text {st }} 2016$

35 Centers for Disease Control and Prevention. Chapter 3: Infectious diseases related to travel - Measles(Rubeola). In: Traveler's health: yellow book. Atlanta, GA: US Department of Health and Human Services, CDC; 2009. Available at http://wwwnc.cdc. gov/travel/yellowbook/2010/chapter-2/measles.aspx. Accessed March $4^{\text {th }}, 2015$

36 Centers for Disease Control and Prevention (CDC). Preventable measles among U.S. residents, 2001-2004. MMWR Morb Mortal Wkly Rep 2005;54(33):817-820

37 Kutty P, Rota J, Bellini W, et al. Measles. In: Roush S, ed. Manual for the surveillance of vaccine-preventable diseases. $6^{\text {th }}$ ed. Atlanta, GA: Centers for Disease Control and Prevention; 2013http:// www.cdc.gov/vaccines/pubs/surv-manual/chpt07-measles.html. Accessed March $10^{\text {th }} 2015$

38 American Academy of Pediatrics. Measles. In: Pickering L, ed. Red Book: 2003 Report of the Committee on Infectious Diseases. 26th ed. Elk Grove Village, IL: American Academy of Pediatrics; 2003: 419-429

39 Fiebelkorn AP, Barkskey A, Hickman C, Bellini W. Mumps. In: Roush S, ed. Manual for the surveillance of vaccine-preventable diseases. $6^{\text {th }}$ ed. Atlanta, GA: Centers for Disease Control and Prevention; 2012http://www.cdc.gov/vaccines/pubs/surv-manual/chpt09-mumps.html. Accessed March $10^{\text {th }} 2015$

40 American Academy of Pediatrics. Mumps. In Pickering L, ed. Red Book: 2003 Report of the Committee on Infectious Diseases. $26^{\text {th }}$ ed. Elk Grove Village, IL: American Academy of Pediatrics; 2003:439-443

41 McLean H, Redd S, Abernathy E, Icenogle J, Wallace G. Rubella. In: Roush S, ed. Manual for the surveillance of vaccine-preventable diseases. $6^{\text {th }}$ ed. Atlanta, GA: Centers for Disease Control and Prevention; 2012http://www.cdc.gov/vaccines/pubs/surv-manual/chpt14-rubella.html. Accessed March $10^{\text {th }} 2015$

42 American Academy of Pediatrics. Rubella. In: Pickering L, ed. Red Book: 2003 Report of the Committee on Infectious Diseases. 26th ed. Elk Grove Village, IL: American Academy of Pediatrics; 2003: 536-541

43 Tejpratap SP, Tiwari MD. Diphtheria. In: Roush S, ed. Manual for the surveillance of vaccine-preventable diseases. $6^{\text {th }}$ ed. Atlanta, GA: Centers for Disease Control and Prevention; 2011http:// www.cdc.gov/vaccines/pubs/surv-manual/chpt01-dip.html. Accessed March $10^{\text {th }} 2015$.

44 American Academy of Pediatrics. Diphtheria. In: Pickering L, ed. Red Book: 2003 Report of the Committee on Infectious Diseases. $26^{\text {th }}$ ed. Elk Grove Village, IL: American Academy of Pediatrics; 2003:263-266

45 Briere EC, Wang X. Haemophilus influenzae. In: Roush S, ed. Manual for the surveillance of vaccine-preventable diseases. $6^{\text {th }}$ ed. Atlanta, GA: Centers for Disease Control and Prevention; 2015http://www.cdc.gov/vaccines/pubs/surv-manual/chpt02hib.html. Accessed March $10^{\text {th }} 2015$

46 American Academy of Pediatrics. Haemophilus influenzae. In: Pickering L, ed. Red Book: 2003 Report of the Committee on Infectious Diseases. 26 ${ }^{\text {th }}$ ed. Elk Grove Village, IL: American Academy of Pediatrics; 2003:293-301

47 Zipprich J, Winter K, Hacker J, Xia D, Watt J, Harriman K; Centers for Disease Control and Prevention (CDC). Measles outbreakCalifornia, December 2014-February 2015. MMWR Morb Mortal Wkly Rep 2015;64(06):153-154 
48 Tunkel DE, Cull WL, Jewett EAB, Brotherton SE, Britton CV, Mulvey HJ. Practice of pediatric otolaryngology: results of the future of pediatric education II project. Arch Otolaryngol Head Neck Surg 2002;128(07):759-764

49 Jacobson Vann JC, Szilagyi P. Patient reminder and patient recall systems to improve immunization rates. Cochrane Database Syst Rev 2005;(03):CD003941

50 Centers for Disease Control and Prevention. National Immunization Survey (NIS)- Children (19-35 months): US vaccination coverage reported via NIS, January-December 2014. http:// www.cdc.gov/vaccines/imz-managers/coverage/nis/child/2014released-child-teen.html. Accessed on February $1^{\text {st }} 2016$

51 World Health Organization. Country Summaries of WHO/UNICEF estimated coverage. http://apps.who.int/immunization_monitoring/ globalsummary/wucoveragecountrylist.html. Accessed February $1^{\text {st }}$ 2016

52 Centers for Disease Control and Prevention (CDC). Summary of notifiable diseases: United States, 2009. MMWR Morb Mortal Wkly Rep 2011;58(53):1-100http://www.cdc.gov/mmwr/preview/mmwrhtml/mm5853a1.htm

53 Center for Disease Control and Prevention. Summary of notifiable disease, United States 2008. MMWR Morb Mortal Wkly Rep 2010; 57(54):1-94
54 Center for Disease Control and Prevention. Summary of notifiable disease, United States 2007. MMWR Morb Mortal Wkly Rep 2009; 56(53):1-94

55 Centers for Disease Control and Prevention (CDC). Summary of notifiable diseases-United States, 2006. MMWR Morb Mortal Wkly Rep 2008;55(53):1-92

56 Center for Disease Control and Prevention. Summary of notifiable disease, United States 2005. MMWR Morb Mortal Wkly Rep 2007; 54(53):2-92

57 Center for Disease Control and Prevention. Summary of notifiable disease, United States 2000. MMWR Morb Mortal Wkly Rep 2002; 49(53):1-102

58 Centers for Disease Control and Prevention (CDC). Summary of notifiable diseases, United States 1995. MMWR Morb Mortal Wkly Rep 1996;44(53):1-87

59 Anderson RM, Hollingsworth TD, Nokes DJ. Mathematical models of transmission and control. In. Detels R, Beaglehole $\mathrm{R}$, Lansang MA, GUlliford $\mathrm{M}$, eds. Oxford Textbook of Public Health. New York: Oxford University Press; 2009; vol. 2:715-744

60 Anderson RM. The concept of herd immunity and the design of community-based immunization programmes. Vaccine 1992; 10(13):928-935 